\title{
INTRODUCING 360-DEGREE VIDEO IN HIGHER EDUCATION: AN OVERVIEW OF THE LITERATURE
}

\author{
Maria Ranieri, Isabella Bruni, Damiana Luzzi, University of Florence, Italy
}

\section{Abstract}

According to international research and institutions, the Higher Education sector needs to deeply innovate his didactic methodologies. In this sense, the integration and use of ICTs have been seen as a possible driver for the improvement of education' quality, and showed good affordances for teaching and learning in terms of engagement, communication and collaboration. New emerging technologies are now under experimentation, especially as for immersive environments from augmented to virtual reality. In this paper we will focus on 360-degree video, offering a first overview of its potential in educational contexts, as they emerge from a systematic literature review.

\section{Introduction}

In the last decades, digital technologies have been viewed as a main factor of innovation of higher education. On one hand, information and communication technologies (ICT) have progressively penetrated academic practices of teaching and learning. More specifically, almost all European universities have undertaken initiatives related to online learning: as emerged from a survey carried out by the European University Association (EUA) in 2013 (Gaebel, Kupriyanova, Morais \& Colucci, 2014), 91\% of Higher Education institutions in Europe deliver blended courses, integrating traditional forms of teaching with online delivery methods, while $82 \%$ declared they offer online courses. This reflects a general trend on a global level, especially considering the industrialized countries. According to a 2013 ECAR international study on the state of digital education at university level (Bichsel, 2013), almost all organizations are interested in online learning: indeed, $80 \%$ offers a high number of online courses, while more than $50 \%$ provides a good number of digital programmes.

On the other hand, ICTs have been seen as a driver for the improvement of quality of education (Hénard \& Roseveare, 2012). Several authors have emphasised the pedagogical affordances of digital devices highlighting their potential for teaching and learning in terms of increased level of collaboration, sharing and networking (Dron \& Anderson, 2014), 
living authentic experiences in safe spaces (see, for example, simulations) (Landriscina, 2012), creating digital artefacts (Hobbs, 2017) and so on. More recently, scholars have analysed the exploitation of digital emerging technologies, such as virtual learning environments (Boulton, Kent, \& Williams, 2018), mobile devices (Crompton \& Burke, 2018), virtual reality (VR) (Freina \& Ott, 2015), augmented reality (AR) (Azuma, 1997), and 360-Degree video (Aguayo et al., 2017). In particular, it is increasing the attention towards computers and visualization technologies as means to improve productivity, quality, and safety in higher education (EDUCAUSE, 2019).

Although these emerging technologies are not new, their educational potential is still under examination. Indeed, the aim of the European Project SEPA360 - Supporting Educators in the Educational Application of 360 video is that of identifying possible benefits on learning related to the innovation of higher education didactics through the use of 360 videos. In this paper we will report some preliminary results of the scoping study carried out in the first months of the SEPA360 project: we will provide an overview of the literature on a specific device, which is 360 -Degree video, which is gaining momentum for its increasing affordability. Before going into the results of the overview, some background is provided on main characteristics of devices supporting visualization for learning in order to better understand the potential of 360-Degree video for educational purposes.

\section{Background}

Recent developments in immersive technologies - as for visualization and interactions have made these devices increasingly attractive to scholars and educators. The latest VR head-mounted displays (HMDs) enable learners to have intensive immersive experiences. In literature, immersion is defined as "a perception of being physically present in a nonphysical world by surrounding the user of the VR system created with images, sound, or other stimuli" which makes user feels to be actually "there" (Freina \& Ott, 2015). In other words, immersion entails for the user to be disconnected with the real world in terms of time and space, while generating a sense of "being" in the task environment.

Looking specifically to VR technologies, they have been largely employed for professional learning and development in high-risk jobs such as engineer, fireman, and soldier mission, but also in higher education. It is based on two of the five senses, that is sound and sighting, and gives a sense of authenticity through a complete sensorial involvement. The standard mode of VR is a 3D animation that "can cause interactively at a mobile computer, commonly by a handle or the remote control so that the image of the digital content shift in some setting" (Jantakoon et al., 2019; p.145).

Great attention has also been payed to AR and the opportunities it offers for improving construction processes in situ. It integrates the physical world with related synthetic data, 
so that virtual and physical objects do co-exist in an augmented space (Azuma, 1997). Several research studies have been carried out on AR applications improving on-site safety performance to some extent (Park, Lee, Kwon, \& Wang, 2013). A crucial feature of AR is its interactivity, which provides relevant potential for teaching, learning and assessment. Students may develop new understandings grounded on experiences and interactions with virtual objects which bring underlying data to life.

As far as 360-degree videos are concerned, they are becoming more affordable (Aguayo et al., 2017), and mobile technologies have become powerful enough to play 360-degree videos (Martín-Gutiérrez et al., 2016). Experiencing real-life classroom events through 3D videos may give to the learners a sensory and imaginary feeling close to real-life experiences. To watch 360-degree videos seems to be more attractive for students since it generates an immersive experience, disconnecting the user from the "real world" (OlmosRaya et al., 2018). It gives also a feeling of presence (Yoh, 2001) and a sense of embodiment (Kilteni, Groten, \& Slater, 2012) in a virtual environment where the learner is engaged in a realistic and authentic situation, although he or she is not physically present.

\section{Methods}

As underlined in the previous paragraph, international research is progressively approaching the theme of immersive technologies in order to evaluate their educational affordances: however, the analysis of the specificities of different technical solutions should be further carried forward, in order to understand possible learning gains and obstacles connected to 360-degree videos, 3D models, virtual and augmented reality. The European project SEPA360 specifically aims at investigating the potentiality of 360 video technology, defined as the results of a video recording that capture the complete surroundings utilizing two or more wide angle lenses and combining their images afterwards. A systematic review of the literature on the topic was realized in order to obtain an overview of current uses of 360 video in educational settings, with a focus on possible application to the higher education field. In this paper, we focus on the use of 360 video in education and answer the following questions:

- How is 360 video currently used in different educational settings and contexts?

- What type of research is carried out on the use of 360 videos?

- What are the technical issues, barriers and opportunities around the use of 360 video?

Based on our results, we draw the state of art of the topic, providing an overview of current literature as for descriptive characteristics, educational context, possible benefits/problems and typology of research design, thus identifying possible gaps to be covered in future research. 


\section{Review process and literature search method}

The systematic review of the literature was conducted according to the PRISMA workflow (Moher, Liberati, Tetzlaff, Altman, \& PRISMA Group, 2009). Six scientific databases were selected due to their coverage of peer-reviewed and educational research (ACM Digital library, EBSCO, ERIC, IEEE Xplore, SCOPUS, Web of Science). The keywords used for the database scan included 360 video written in different ways and possible educational areas of use. The query adopted was ("360 video" OR “360 degree video" OR “360-degree video" OR “360" video") AND (“education" OR "university" OR "higher education” OR “"professional development" OR "school”): a time and language constraint was applied in order to select only English contributions of the last 10 years. This search yielded 1024 papers: 38 were duplicates and were removed, thus obtaining 986 for the screening phase. In this phase, papers were excluded according to the following criteria: (a) focus only on technological topics or tools; (b) focus on simulation and virtual reality; (c) superficial use of the 360 video: the technology was mentioned, but not used for or central to the research. According to these criteria, 933 papers were excluded and 53 papers were considered for full-text analysis: at the end of the whole process, 28 papers were considered for the systematic review.

\section{Data analysis}

As for the analysis, the papers were coded and classified into different categories, which were defined by the SEPA360 team of researchers in the first project transnational meeting. One researcher therefore proceeded with the codification of the 28 papers, adopting the criteria discussed within the research group.

The fields identified attempted to capture: (a) the general document identity (Authors, Title, Year, Source Title, Publication Type, Geographical Area); (b) the research design (Research Area, Educational Level, Type of learning, Aim of the study, Type of study design, Type of Data Collected, Data Analysis Method, Sample); (c) the benefits and challenges of pedagogical application of 360 video (Learning gains, Benefits, Technical challenges). Underlying Theories, Methodological Approach, Research Applications). The data collected were analysed with descriptive statistics in order to summarize the variables studied.

\section{Results}

In this section, we present the results according to the main categories and criteria of analysis explained in the previous sections, combining the data in order to gain a better understanding of the findings. 
As a first step, we analysed the publications considering basic information about the documents such as year of publication, geographic area and document type. As shown in Graphs 1 and 2, it emerges that Europe is the geographical area with the highest number of publications (14), while it stands out South America and Africa have no one. As for number of publications, it has increased in the past three years (2017 to 2019), both for conference proceedings (18) and for journal papers (10). This trend highlights and confirms that the interest and use of 360 video is on the rise.

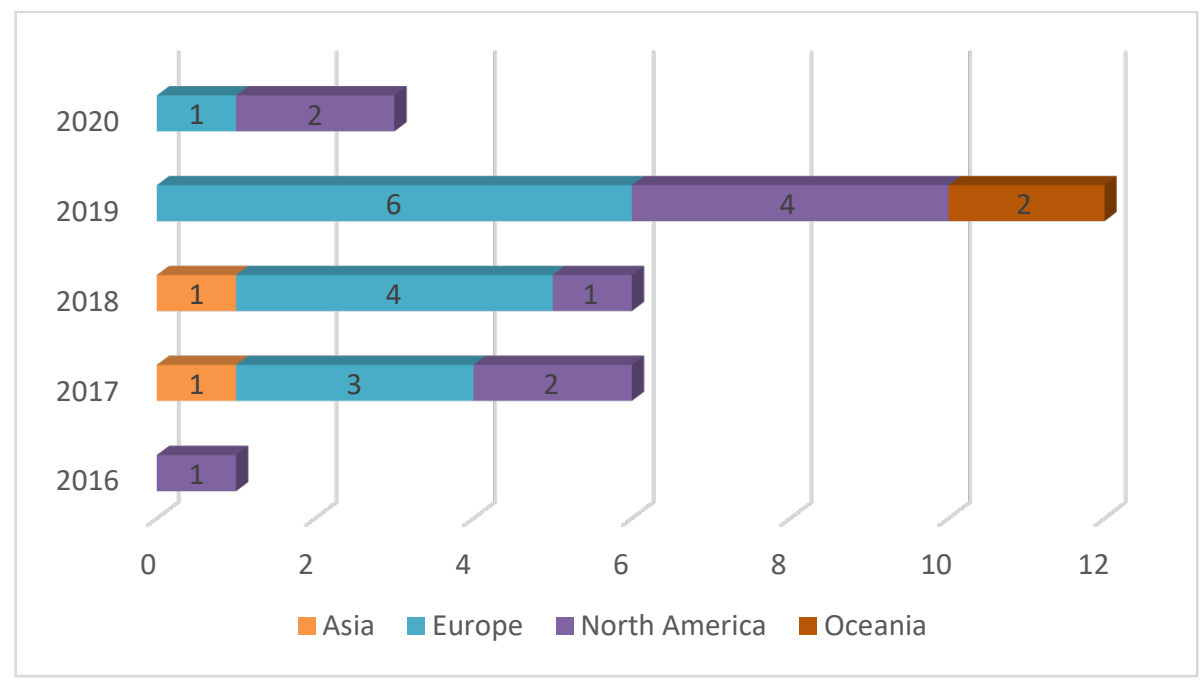

Figure 1. Number of publications per year divided by geographical are. The colour shows the details of the geographical area.

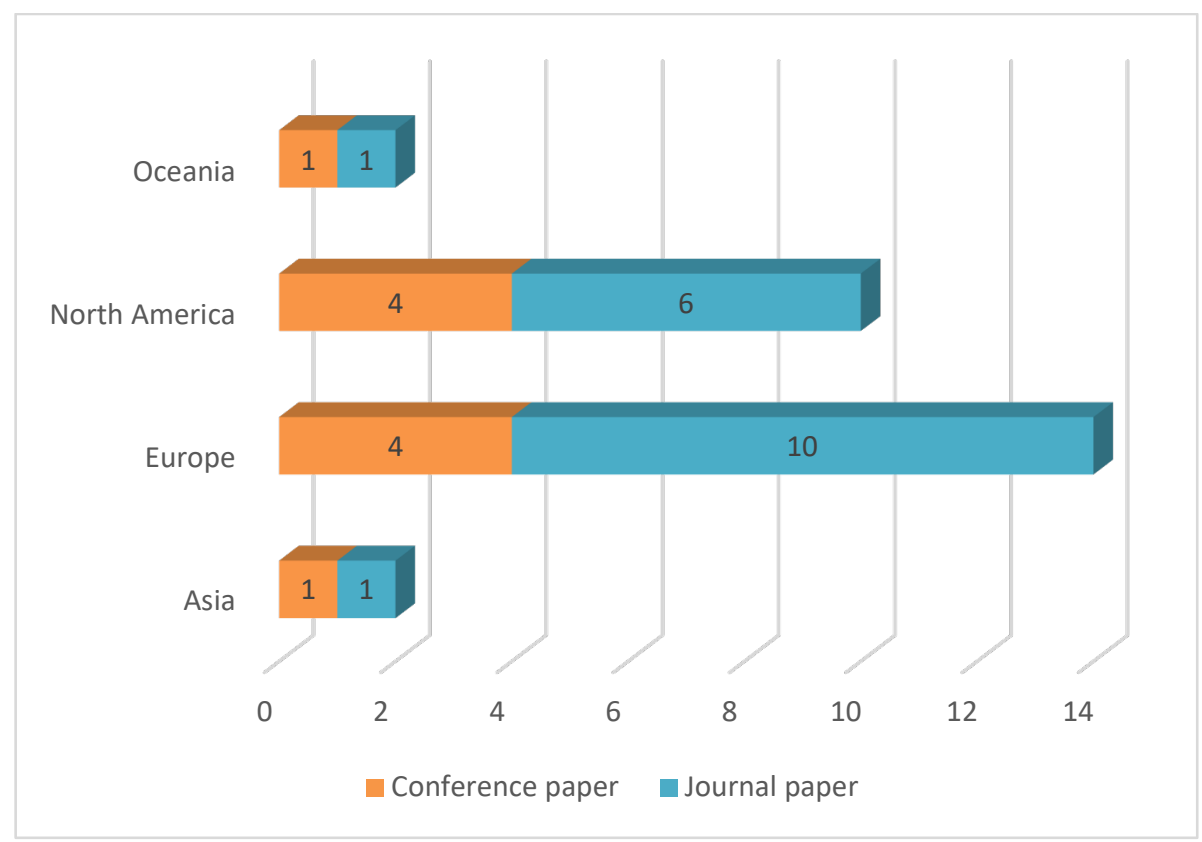

Figure 2. Number of publications per geographical area divided by document type. The colour shows the details of the document type.

Secondly, we analysed the publications according to the categories referred to the research design and results (Table 1). As for the educational context, most publications refer to 
Higher education (24) and formal settings (27). Continuing the observation of the context, it is confirmed that the research area that denotes the greatest interest is the Scientific research area (Health Science, Science and Engineering) (11) followed by Education and Teacher Education (8). In these areas the 360 video is used in a profitable way to simulate operative procedures, laboratory experiments, physical environment, check which are the best technologies and the optimal workflow to make 360 video, and record the teacher in the classroom while conducting the lesson and analysing his work for understanding all the aspect of teaching. Unlike traditional video recordings, which usually provide a very restrictive perspective of an object, person or environment, 360 videos provide users with full spherical view, in order to enhanced realism, and make the experience more immersive and engaging.

Indeed, due to the greater interaction with content and environment, another area in which the interest in the use of 360 video is growing is Sport and Physical education (2) in adult learning and Higher education. The situated learning approaches with 360 videos evoke student to explore new learning behaviours and experience and make proactive adjustments on them.

Focusing on the students, learning gains and some problems emerge in the use of 360 video. The greatest benefits are obtained in terms of engagement (9) and, therefore, of learning, as thanks to the 360 video, compared to the $2 \mathrm{D}$ video, it is possible to keep students more involved, improve their attentiveness (6) and provide them with an enjoyable experience (13). The 360 video enable new viewing angles and learning scenarios that would not be possible without 360 video-techniques. A further benefit in the use of the 360 videos compared to the simulations made with VR, is the reduction in costs (4) necessary for their realization.

Table 1: Context, Benefits and problems as for learners or institutions

\begin{tabular}{|c|c|c|c|c|c|c|c|}
\hline & & Year & 2016 & 2017 & 2018 & 2019 & 2020 \\
\hline & & Arts \& Humanities & & & 3 & 1 & \\
\hline & & Business & & 1 & & & \\
\hline & & Commerce & & & 1 & & \\
\hline & & Education & 1 & 2 & & 1 & \\
\hline & Research area & Engineering & & & & 1 & \\
\hline & Researchl dred & Health Sciences & & 1 & 2 & 3 & 1 \\
\hline & & Teacher Education & & & & 3 & 1 \\
\hline & & Science & & & & 3 & \\
\hline \multirow[t]{9}{*}{ Context } & & Social Science & & & & & 1 \\
\hline & & Sport/Physical Education & & 2 & & & \\
\hline & & Adult Learning & & 1 & 1 & & \\
\hline & Fducationall level & Higher Education & 1 & 4 & 5 & 11 & 3 \\
\hline & cuucational Level & Primary School & & 1 & & 2 & \\
\hline & & Secondary School & & 2 & & & \\
\hline & & Formal & 1 & 6 & 5 & 12 & 3 \\
\hline & Type of learning & Informal & & & 1 & & \\
\hline & & Non-Formal & & & & & \\
\hline
\end{tabular}




\begin{tabular}{|c|c|c|c|c|c|c|c|}
\hline \multirow{13}{*}{$\begin{array}{l}\text { Focus on } \\
\text { learners }\end{array}$} & \multirow{9}{*}{ Learning gains } & Attentiveness & & 1 & 1 & 3 & 1 \\
\hline & & Cognitive skill & & & & 1 & 1 \\
\hline & & Engagement & & 3 & 2 & 4 & \\
\hline & & Information retention & 1 & & 3 & 1 & 1 \\
\hline & & New learning behaviours & & & 1 & & \\
\hline & & Reflective activities & & & 1 & 1 & \\
\hline & & Technical skill & & & 1 & & \\
\hline & & Transfer of knowledge & & 1 & 2 & 3 & \\
\hline & & Not specified & & 2 & 1 & 1 & 1 \\
\hline & \multirow{4}{*}{$\begin{array}{l}\text { Learners reactions / } \\
\text { problems }\end{array}$} & Enjoyable experience & & 3 & 2 & 6 & 2 \\
\hline & & Experienced technical hindrances & & & & 1 & 1 \\
\hline & & Physical discomfort & & 1 & 3 & 5 & 1 \\
\hline & & Not specified & & 2 & 3 & 5 & \\
\hline \multirow{3}{*}{$\begin{array}{l}\text { Focus on } \\
\text { institutions }\end{array}$} & \multirow{3}{*}{ Benefits } & Cost & & 1 & 3 & & \\
\hline & & Scalability & & 1 & 3 & 2 & \\
\hline & & Not Specified & 1 & 4 & 2 & 7 & 3 \\
\hline
\end{tabular}

In spite of what one might commonly think, only seven publications reported problems in using the 360 video, detecting cases of uncomfortable feelings while using viewer headset: some students suffered from dizziness, nausea, anxiety about interaction or double vision. One publication conclude that it is harder to watch an immersive video as a class in a coordinated way, and it suggests that it is preferable to use it primarily for homework. Two other publications have mainly studied motion sickness and the results show that none of the students highlighted that physical discomfort.

\section{Conclusion}

The results of the systematic literature review showed that research on 360-degree video has grown in the last three years still but it is still at his infancy: the topic is usually overlapping with different immersive solutions such as virtual or augmented reality that have been already fully experimented in educational contexts. Another limitation of current literature refers to the type of researches carried out: papers mostly describe application experiences, without providing affordable data on learning outcomes. Nevertheless, 360-degree video shows possible benefits in terms of students' involvement and satisfaction, even if the use of headset viewer can produce some physical or psychological reaction.

\section{References}

Aguayo, C., Cochrane, T., \& Narayan, V. (2017). Key themes in mobile learning:

Prospects for learner-generated learning through AR and VR. Australasian Journal of Educational Technology, 33(6), 27-40. https://doi.org/10.14742/ajet.3671

Azuma, T. R. (1997). A survey of augmented reality. Presence, 6, 355-385. https://doi.org/10.1162/pres.1997.6.4.355

Bichsel, J. (2013). The state of e-learning in higher education: An eye toward growth and increased access. EDUCAUSE Center for Analysis and Research. Louisville, CO. 
Bulton, C. A., Kent, C., \& Williams, H.T.P. (2018). Virtual learning environment engagement and learning outcomes at a 'bricks-and-mortar' university. Computers \& Education, 126, 129-142.

Crompton, H., \& Burke, D. (2018). The use of mobile learning in higher education: A systematic review. Computers \& Education, 123, 53-64.

Dron, J., \& Anderson, T. (2014). Teaching Crowds - Learning and Social Media. Edmonton: AU Press.

EDUCAUSE. (2019). EDUCAUSE Horizon Report. 2019 Higher Education Edition. Louisville, CO: EDUCAUSE.

Freina, L., \& Ott, M. (2015). A Literature Review on Immersive Virtual Reality in Education: State Of The Art and Perspectives. In Proceedings of eLearning and software for education, 133-141.

Gaebel, M., Kupriyanova, V., Morais, R., \& Colucci, E. (2014). E-Learning in European Higher Education Institutions. Brussels: European University Association (EUA).

Hénard, F., \& Roseveare, D. (2012). Fostering Quality Teaching in Higher Education: Policies and Practices. Paris: OECD Publishing.

Hobbs, R. (2017). Create to Learn: Introduction to Digital Literacy. Hoboken, NJ: Wiley. Jantakoon, T., Wannapiroon, P., \& Nilsook, P. (2019). Virtual Immersive Learning Environments (VILEs) Based on Digital Storytelling to Enhance Deeper Learning for Undergraduate Students. Higher Education Studies, 9(1), 144-150.

Kilteni, K., Groten, R., \& Slater, M. (2012). The sense of embodiment in virtual reality. Presence: Teleoperators and Virtual Environments, 21(4), 373-387. https://doi.org/10.1162/PRES_a_00124

Landriscina, F. (2013). Simulation and Learning. A Model-Centered Approach. Berlin: Springer.

Martín-Gutiérrez, J., Mora, C. E., Añorbe-Díaz, B., \& González-Marrero, A. (2016). Virtual technologies trends in education. EURASIA Journal of Mathematics Science and Technology Education, 13(2), 469-486. https://doi.org/10.12973/eurasia.2017.00626a

Moher, D., Liberati, A., Tetzlaff, J., Altman, D. G., \& PRISMA Group. (2009). Preferred reporting items for systematic reviews and meta-analyses: The PRISMA statement. PLoS Medicine, 6(7), e1000097. https://doi.org/10.1371/journal.pmed.1000097 
Olmos, E., Cavalcanti, J. F., Soler, J.-L., Contero, M., \& Alcañiz, M. (2018). Mobile virtual reality: A promising technology to change the way we learn and teach. In S. Yu, M. Ally, \& A. Avgoustos (eds.), Mobile and ubiquitous learning, perspectives on rethinking and reforming education (pp. 95-105). Singapore: Springer Nature. https://doi.org/10.1007/ 978-981-10-6144-8_6

Park, C. S., Lee, D. Y., Kwon, O, S., \& Wang, X. (2013). A framework for proactive construction defect management using BIM, augmented reality and ontology-based data collection template. Automation in Construction, 33, 61-71. https://doi.org/10.1016/j.autcon.2012.09.010

Yoh, M.-S. (2001). The reality of virtual reality. Proceedings of the Seventh International Conference on Virtual Systems and Multimedia, 7, 1-9. https://doi.org/10.1109/VSMM.2001.969726 